\title{
UNA REFLEXIÓN SOBRE LA ECONOMÍA DE ESPAÑA Y DE SUS POSESIONES ULTRAMARINAS EN TORNO A 1898
}

\section{JUAN VELARDE FUERTES}

En torno al centenario de 1898 se han multiplicado las aportaciones sobre lo sucedido en España en el paso del siglo XIX al XX. En muchos sentidos, resultan decisivos los acontecimientos en los cuatro ámbitos de Cuba y Puerto Rico en el Caribe, y de Filipinas y de los archipiélagos del Pacífico - Marianas con Guam al Norte, y Carolinas y Palaos al Sur-, donde en 1898, por el Tratado de París, y en 1899, en virtud de un acuerdo con Alemania, se abandonaron todas estas posesiones.

En principio, el sentimiento fue de catástrofe en todos los sentidos. Desde el punto de vista económico, Costa lo señaló en su alegato El conflicto de la Micronesia y lo subrayó en su discurso de ingreso en la Real Academia de Ciencias Morales y Políticas. Pío Pita Pizarro había indicado más de medio siglo antes que era necesario explotar «la finca cubana». Además los enlaces mercantiles de Filipinas, Cuba y Puerto Rico con la metrópoli pasaron a ser muy fuertes. Con Cánovas del Castillo constituyeron un elemento nada despreciable para alcanzar un deseado equilibrio para nuestra economía castiza. Ésta se sostenía gracias a llegadas de fondos del exterior. Las inversiones de capitales, las exportaciones de vino y de minerales metálicos y las de azúcar, tabaco y, en menor medida, de café y otros productos tropicales, se integraban dentro de un vasto proceso macroeconómico, con una fuerte protección para el trigo y las harinas, con el tráfico marítimo, con la producción de textil, con la siderometalúrgica, con la carbonera, con un régimen fiscal basado en los Conciertos de Navarra y las tres provincias vascongadas $y$, por supuesto, con la existencia pacífica de una importante masa de esclavos y culis chinos, sobre todo en Cuba, garantizada por nuestro gasto público en fuerzas armadas y de seguridad que ponía a los hacendados a salvo del riesgo de un alzamiento parecido al acontecido en la isla de Santo Domingo. Cánovas del Castillo incluso intentó añadir a todo una protección social basada, en más de un sentido, en los modelos de Bismarck. 
Pronto seis acontecimientos transformarían este panorama: la violencia de los asalariados en la ciudad y el campo, manifestada a través de partidos y sindicatos de notable agresividad; la presión internacional e interior que obligó a liberar en la década de los ochenta, o sea, muy tardíamente, a los esclavos; los reiterados alzamientos independentistas en Cuba; una rebelión musulmana prolongada en Filipinas que se agregaba a un independentismo muy original; la presión alemana en los archipiélagos del Pacífico; finalmente, la guerra con los Estados Unidos. Pronto los euskalerriakos y la Reinaixença acabarían por introducir nuevas perturbaciones.

Naturalmente, ese pretendido juego de pesos y contrapesos económicos, que Cánovas del Castillo tejió para mantener trabadas social y políticamente partes muy diversas del tejido hispano, se vino estrepitosamente al suelo. La convicción muy popular en España era la de que con el modelo canovista todos ganaban, aunque no ganasen cifras considerables; ahora, al ser destruido, en buena parte por los acontecimientos que se escalonan entre 1878, paz del Zanjón, y 1899, cesión de la Micronesia a Alemania, se pasaba a opinar que una catástrofe económica iba a ser general. ¿Fue, realmente, así?

El aclarar esa cuestión ha sido el centro de un esfuerzo muy importante efectuado por los investigadores de la historia económica de España, Cuba, Filipinas y Puerto Rico, que se abrió en 1995 con el libro de Manuel Moreno Fraginals, Cuba/España. España/Cuba. Historia común ${ }^{1}$ y que, al menos por ahora, se cierra con los libros de Jordi Maluquer de Motes, España en la crisis de 1898. De la Gran Depresión a la modernización económica del siglo $\mathrm{XX}^{2}$, y el dirigido por Pedro Tedde, Economía y Colonias en la España del $98^{3}$. La obra de Maluquer de Motes es, efectivamente, la última de esta serie, pero como colabora, casi a modo de preámbulo de su libro, en el volumen dirigido por el profesor Tedde de Lorca, prefiero reflexionar sobre un conjunto espléndido de puntos de vista y novedades que se ofrecen en el libro dirigido por el último profesor, al hilo de todos y cada uno de sus autores. El conjunto creo que constituye un friso que responde, del modo adecuado, a la pregunta planteada.

Aparte de una intervención mía, titulada «El 98: las nuevas ideas económicas y sus consecuencias» y que abre el volumen, que se comprende

\footnotetext{
1 Crítica, Barcelona, 1995, presentación de Josep Fontana, 310 pp.

2 Ediciones Península, Barcelona, 1999, 235 pp.

'Ediciones Síntesis, Fundación Duques de Soria, Madrid, 1999, 349 pp.
} 
que discurre por terrenos bien ajenos a la cuestión que aquí abordo ${ }^{4}$, el libro se divide en tres grandes partes. La primera se centra en la aportación de Pedro Tedde de Lorca, titulada «La economía española en torno al 98». Tres grandes partes constituyen su esencia. La primera, la evolución de la población y de los sectores productivos desde el inicio de la Restauración (1875) a la Primera Guerra Mundial (1913). Comienza, pues, esta aportación con este análisis minucioso, que sirve también para reaccionar contra ciertos planteamientos de la sabiduría convencional. Se lee en la p. 82: «Recientemente los historiadores de la industria han subrayado la importancia de otros subsectores, diferentes de los clásicos algodonero, siderúrgico y químico (además de la energía), los cuales recibieron la aten-

+ Aparte de que corresponde a otros enjuiciar mi aportación, sobre estos asuntos de 1898, en el período que va de 1997 a 1999, publiqué, en relación con estas cuestiones, «Reflexión desde la economía de Cánovas del Castillo», en Antonio Cánovas del Castillo. Homenaje y memoria de la Real Academia de Ciencias Morales y Politicas (1897-1997), Real Academia de Ciencias Morales y Políticas, Madrid, 1997, pp. 333-345; «Introducción en forma de reflexión sobre el 98», en el libro que coordiné, Perspectivas del 98, un siglo después, Junta de Castilla y León, Consejería de Educación y Cultura, Ávila, 1997, pp. 11-25; «Ideas económicas de Cánovas del Castillo», en Cánovas (1828-1897), tomo II, documento 7.048/3, Universidad Internacional Menéndez Pelayo, Valencia, 1997, pp. 1-34; «El significado económico de las Antillas», en el libro dirigido por Emilio de Diego, Hacia el 98. La España de la Restauración y la crisis colonial 1805-1898, Cuadernos de la Escuela Diplomática, 12, Madrid, 1997, pp. 171-175; «La economía española en 1898, ¿Desastre o cambio?», en Instituto de Historia y Cultura Naval, XVI Jornadas de Historia Marítima, «Aspectos navales en relación con la crisis de Cuba (1895-1898)», Ciclo de conferencias, octubre 1997, Cuadernos Monográficos del Instituto de Historia y Cultura Naval, núm. 30, Madrid, 1997, pp. 7.22; «Prólogo, o los motivos del interés para un economista de la figura de Cánovas del Castillow, en Antonio Cánovas del Castillo, Obras Completas, tomo IV, Escritos de Economia y Política, Fundación Cánovas del Castillo, Madrid, 1997, pp. 7-87; «Una interpretación del 98», en España entre dos siglos, en torno al 98, en el Catálogo de la exposición de objetos de 1898 montada por Ibercaja, Zaragoza, 1998, pp. 57-65; «Notas para una exposición castellana de artes plásticas en torno a 1898», en 1898, Castilla y León, Exposición y Catálogo, Junta de Castilla y León, (Valladolid), 1998, pp. 22-34; «Introducción. La Real Academia de Ciencias Morales y Políticas ante 1898: proemio», en Papeles y Memorias de la Real Academia de Ciencias Morales y Políticas, junio 1998, núm. III, pp. 3-15; «Los economistas de la generación del 98», en Papeles y Memorias de la Real Academia de Ciencias Morales y Políticas, junio 1998, núm. III, pp. 3-15; «1898 o la construcción del modelo económico castizo español», en Torre de los Lujanes, junio 1998, núm. 36, pp. 127-138; «La economía del 98», en Instituto de Historia y Cultura Naval, Visiones de ultramar. El fracaso del 98, Cuadernos Monograficos del Instituto de Historia y Cultura Naval, núm. 32, Madrid, 1998, pp. 33-44; Juan Velarde: «El 98 convirtió Asturias en un distrito industrial», en La Nueva España de Gijón, 28 enero 1999, año LXIII, núm. 20.138, p. 6; «Una reflexión sobre la economía española del siglo XIX», en el volumen coordinado por Juan Velarde Fuertes y Emilio de Diego García, Castilla y León ante el 98, Junta de Castilla y León. Consejería de Educación y Cultura, Valladolid, 1999, pp. 77-92; finalmente, «El 98: las nuevas ideas económicas y sus consecuencias», en Pedro Tedde, director del libro Economia y Colonias en la España del 98 , ob. cit., pp. 19-78. 
ción de los especialistas, atraídos por el modelo de industrialización británica. Jordi Nadal, basándose en datos fiscales, estima que, en 1900, la industria fabril alimenticia ocupaba el primer lugar en el sector, por delante de las textiles, pudiendo estar la diferencia entre ambas en torno al 50 por 100. Dentro de los subsectores de la industria alimentaria hay dos que tuvieron una implicación directa con lo ocurrido en 1898 . Me refiero a la industria azucarera y a la harinera.» La segunda de las partes de este trabajo es la referente a Banca y moneda. Se inicia con el examen de la situación del Banco de España que, justo en 1900, va a experimentar una transformación muy importante, que le llevará de ser un Banco privilegiado y fundamental, a ser un Banco de bancos, que además había abandonado en 1883 «de facto el patrón bimetálico instaurado en 1868, al suspender el canje de los billetes en oro» (p. 87). Naturalmente, no puede extrañarnos que la peseta iniciase, durante los últimos lustros del siglo XIX, «una devaluación en relación con el franco francés, la libra esterlina y otras monedas» (p. 88). Además, nace una importante banca privada. «La principal característica - señalará el profesor Tedde- de algunos de estos nuevos intermediarios financieros sería su carácter de banca mixta o universal, es decir, dedicada a diferentes prestaciones financieras y a la inversión directa en otros sectores de la economía» (p. 89). Finalmente, el estudio de Tedde concluye con un análisis de la Hacienda Pública. Con apoyo más remoto en la reforma Mon-Santillán, gracias a la reforma Villaverde existen algunas novedades interesantes en el planteamiento fiscal español. Como dice el profesor Tedde, «la tercera clave de la reforma de Fernández-Villaverde —además de la tributaria y la monetaria - fue la contención de la deuda pública, especialmente la del Tesoro, también denominada deuda flotante» (p. 93), con tres consecuencias: «la caída del tipo de interés — del 4,51 por 100 en 1874 a 3,74 por 100 en 1900-, el incremento de la renta per cápita en un 11,5 por 100 , en términos reales, entre 1895 y 1903, y la recuperación del tipo de cambio de la peseta, tras la devaluación sufrida en el último decenio del siglo XIX» (p. 94).

La segunda parte de este libro se titula «España y las Antillas a finales del siglo XIX» y se divide en seis capítulos. El primero de ellos se debe a Jordi Maluquer de Motes Bernet y se titula «El impacto de las guerras coloniales de fin de siglo sobre la economía española». Se trata de una síntesis, o, si se quiere, de un preludio, especialmente bien hecho, del libro del propio Maluquer de Motes, España en la crisis de 1898. De la Gran Depresión a la modernización económica del siglo $X X^{5}$, uno de los mejo-

\footnotetext{
5 Ob. cit.
} 
res estudios realizados sobre este período y de empleo obligado además. Hay una línea directa desde Lacombe —en 1901- a Cristian Eckert -en 1918 - y Maluquer de Motes, cuando éste puntualiza que «la pérdida de los mercados coloniales, a nivel del conjunto de la economía, no provocó ninguna alteración significativa. Las relaciones con Cuba todavía mejoraron en términos de balanza bilateral. El brote inflacionista de las guerras resultó perfectamente inocuo. La economía española, en fin, atravesó el supuesto desastre del período bélico en condiciones de auténtico auge económico» (p. 118).

El segundo de los capítulos se debe a Inés Roldán de Montaud. Bajo el epígrafe de «La Hacienda cubana en el período de entreguerras (1878-1895)», aborda una cuestión interesantísima que se había dejado de investigar después del preludio que sobre estas cuestiones se hizo por el matemático y economista marginalista Vázquez Queipo, asesor, además, de Martínez Campos. El grave problema de la Deuda que recae sobre los hombros cubanos centra buena parte de este trabajo. Dice muy bien Inés Roldán de Montaud que «si la autonomía implicaba libertad arancelaria exigía también una reordenación de las relaciones financieras entre colonia y metrópoli; un nuevo reparto de las cargas tributarias y de las obligaciones financieras de la Deuda colonial. Esto fue, sin duda, un elemento que contribuyó a dificultar el camino hacia el régimen autonómico rechazado de forma sistemática por los grandes partidos de la Restauración hasta bien entrado el año 1897» (p. 153). Después, bien sabido es que no hubo tiempo ya para nada, con lo que se consiguió que en la paz de París se rechazase por los comisionados norteamericanos la responsabilidad de la deuda de Cuba. Al final, hubo de poner orden, situando su carga, no sobre hombros cubanos, sino sobre los españoles, por ese político ejemplar que fue Raimundo Fernández Villaverde.

Manuel Martín Rodríguez, con su maestría habitual, se ocupa del tercero de los capítulos, titulado «El azúcar y la política colonial española (1860-1898)». Moreno Fraginals y sus investigaciones viejas - por supuesto, El Ingenio ${ }^{6}$ - y nuevas, popularizaron - recordemos sus alusiones a la sacarocracia ${ }^{7}$ - las cuestiones del azúcar cubano, pero faltaba integrarlas en las del azúcar peninsular, lo que se hace de modo perfecto aquí. Como señala el profesor Martín, «con una industria nacional (textil y harinera)

' Cfr. Manuel Moreno Fraginals, El Ingenio. Complejo económico social cubano del azúcar, Editorial de Ciencias Sociales, La Habana, 1978.

7 Véase el capítulo Los oligarcas se toman sacarócratas, en Manuel Moreno Fraginals, Cuba/España. España/Cuba. Historia común, ob. cit., pp. 145-156. 
escasamente competitiva y enormemente dependiente del mercado colonial, una cada vez más potente y autosuficiente industria azucarera peninsular (de caña y de remolacha), y unos mercados internacionales azucareros cada vez más saturados y bajistas, las relaciones comerciales de España con sus colonias y las de éstas con terceros países tuvieron que modificarse sustancialmente entre 1882 y 1898 , y en una dirección que las empujaba inexorablemente hacia los Estados Unidos, el único gran mercado potencial de su casi único producto» (p. 171). Si reflexionamos, ahí tenemos expuesto buena parte del armazón íntegro de mucho de lo que sucedió, con el centro en Cuba, entre Estados Unidos y España.

El cuarto capítulo, escrito por Oscar Zanetti Lecuona, del Instituto Nacional de Historia de Cuba, es el titulado «Raíces del 98: España y el problema económico cubano a finales del siglo XIX». Me atrevo a decir que su núcleo más interesante radica en la exposición de la crisis derivada de los altos tipos de interés que pesaban sobre la economía cubana, fruto de una escasez de capitales en una isla con unas cifras altísimas de exportaciones por habitante y «frecuentes superávit» en la balanza comercial (p. 184). Ante este cuadro, Oscar Zanetti Lecuona considera que queda explicado «que los intereses económicos insulares se movilizasen exigiendo soluciones del gobierno madrileño (que)... en lo esencial, apuntaban hacia una reducción de la carga tributaria, la reforma del arancel de aduanas, la reducción del presupuesto de gastos y la adopción de una política comercial que promoviese las exportaciones cubanas» (p. 185). Todo esto engranaba muy mal con la política económica de la Restauración. Por eso, la posibilidad de algún tipo de acuerdo se rompe al presentarse los 24 puntos de 1891. Se pretendía con este movimiento económico, como escribe Zanetti Lecuona, «un arreglo comercial con Estados Unidos, una reforma arancelaria "amplia y radical", la total eliminación de derechos de exportación, la franquicia para la introducción de productos cubanos en la Península y otras medidas de estimulación comercial; se demandaba la reducción del gasto público en correspondencia con las posibilidades contributivas del país, la suspensión de los pagos de la Deuda y la participación de la metrópoli en la amortización de ésta, así como medidas de más franca proyección política, tales como la eliminación del sistema de autorizaciones para proveer las medidas requeridas por la economía cubana y una garantía de la participación del país mediante sus corporaciones, en la elaboración de los presupuestos y el establecimiento del régimen arancelario» (p. 197).

El quinto capítulo, «Cuba 1898: inventario para una neocolonia», es obra de Alejandro García Álvarez, profesor de la Universidad de La Haba- 
na. En él se presenta un panorama sintético de cómo, desde 1899, la presencia norteamericana en Cuba hizo posible que se transformase la isla «en una neocolonia» ${ }^{8}$. En ese sentido un punto de apoyo importante, que también había explorado Alejandro García Álvarez con Oscar Zanetti, fue el de las investigaciones que el ejército de ocupación norteamericano efectuó sobre «la situación de la agricultura cubana y sus posibilidades para la inversión de capitales, el estado de la infraestructura productiva y de servicios, la situación del crédito y otros aspectos de especial interés económico» (p. 126). Me atrevo a decir que hay que trabajar más a fondo esta hipótesis, porque, en principio, me parece que puede ligarse al famoso sofisma de post boc, ergo propter boc ${ }^{9}$.

El capítulo sexto y final de esta parte lleva por título «Cuba y Puerto Rico en la crisis del colonialismo español: condiciones económicas (1890-1897)» y es obra de Astrid Cubano Iguina, profesora de la Universidad de Puerto Rico, en el recinto de Río Piedras. Gracias a este estudio queda claro que «las condiciones de la economía en Puerto Rico eran muy distintas» (p. 223) a las cubanas, entre otras cosas porque «si en Cuba el recurso más importante era la tierra, en la pequeña Antilla era la numerosa población campesina» (ibidem). En este sentido actuaron, para que existiese «una clase jornalera abundante», las «leyes contra la vagancia, especialmente el Reglamento de jornaleros de 1849» (ibidem). Todo esto es lo que explica la aparición de las «partidas sediciosas», esto es, «bandas de hombres armados que saqueaban tiendas y fincas de café» (p. 225), perpetrando a veces actos de agresión física contra los propietarios. Proliferaron en 1898 con el súbito vacío de la vigilancia rural y urbana que dejó la invasión del ejército de los Estados Unidos y la retirada de las autoridades españolas. «Atacaron fincas de españoles y criollos sin que hubiera orientación clara en sus actos» (ibidem). Astrid Cubano Iguina ha de confesar que «Puerto Rico -en 1898- destacaba por su renuncia a formular proyectos nacionales según el modelo latinoamericano y por la falta de metas colectivas. La movilización popular no superó el plano de lo apolítico y la guerra social. Las primeras manifestaciones de opinión política popular, después de establecida la dominación norteamericana en

${ }^{8}$ La expresión la emplea también Alejandro Garcia Álvarez en su trabajo «El 98, un puente para el desarrollo neocolonial de Cuba», en la obra dirigida por Salvador Palazón Fernando y Candelaria Sáiz Pastor, La ilusión de un Imperio. Las relaciones económicas bispano-cubanas en el siglo XIX, Universidad de Alicante, Alicante, 1998, pp. 119-139.

'Se refiere, indudablemente, Alejandro García Álvarez al Report of the Census of Cuba. 1899, editado por el US War Department, Washington, 1900. 
1898, fueron de índole urbana y radical, y ratificaron la ola de anexionismo a los Estados Unidos. Aun los autonomistas, que poco antes se habían mantenido fieles a la identidad española, se planteaban - véase el artículo de Luis Muñoz Rivera el 7 de septiembre de 1899- la necesidad de obtener "la identidad norteamericana" en plano de igualdad con otros Estados de la Unión, como única vía rápida al progreso» (pp. 227-228).

La parte tercera se dedica a «La economía financiera española después del 98». Comprende cinco capítulos. El primero, de Francisco Comín, analiza «La reforma en la Hacienda de Fernández Villaverde». Era un reto difícil, porque daba la impresión de que, tras algunas aportaciones muy importantes, como la de Gabriel Solé Villalonga ${ }^{10}$, ya estaba casi todo dicho. Sin embargo, el buen hacer del profesor Comín no sólo consigue aqui una excelente síntesis de lo ya sabido, sino que acierta a poner las cosas en sus justos términos. Por eso, dice (p. 252), «siendo importante la obra de Villaverde, ha tendido a ser sobrevalorada, en mi opinión. Hay que dejar claro que consiguió casi todos los fines que buscaba; pero, fundamentalmente, sus objetivos fueron muy concretos y de corto alcance. En primer lugar, el mérito debe ser compartido con los ministros que le sucedieron y que continuaron su labor. En segundo lugar, el control del gasto público logró el superávit, pero su plan de estabilización tuvo costes sobre el crecimiento, al paralizar proyectos de inversión pública. En tercer lugar, su reforma tributaria fue más modesta de lo supuesto hasta ahora y enseguida mostró sus insuficiencias. Donde la obra de Villaverde adquiere un mayor éxito fue en el arreglo de la Deuda (que tuvo costes para los tenedores de la interior) y en el control monetario». Efectivamente, es así. Por eso el efecto más notable de la reforma de Villaverde se encuentra en lo no buscado por él, como sucede con la transformación, ya señalada, del Banco de España, y con la creación de una Banca privada de tipo universal.

De ahí el interés de la aportación segunda de esta parte, de José Luis García Ruiz, en el capítulo «La nueva banca mixta en el Madrid de comienzos de siglo». Aparentemente es un inventario, una crónica de la evolución bancaria hasta 1913 y un relato de la crisis de 1913 en relación con el Banco Hispanc Americano. El empleo de fuentes inéditas transforma este capítulo en uno de imprescindible consulta, de ahora en adelante, para todos los estudiosos. El que, por ejemplo, así se conozca, históricamente,

${ }^{10}$ Cfr. Gabriel Solé Villalonga, La reforma fiscal de Viliaverde: 1899-1900, Editorial de Derecho Financiero, Madrid, 1967. 
un antecedente del Pacto de Las Jarillas, no deja de ser extraordinariamente interesante.

El tercero de los capítulos es obra de Manuel J. González, y se titula «El Banco de Bilbao y el resurgir de la Banca vizcaína a comienzos de siglo». Efectivamente, ésta era una cuestión a exponer, porque el bloque de los grandes bancos que se ponían en marcha en torno a 1898 surge ex novo, salvo el caso del Banco de Bilbao. En torno a esto se agolpan varios acontecimientos: aumento de la competencia bancaria en la plaza bilbaína; la caída en el incremento de la producción de mineral de hierro, en buena parte ligada a la decadencia de la última parte de la Era Victoriana; las cuestiones relacionadas con el proteccionismo en el mundo vizcaíno; finalmente, el talante, excesivamente prudente quizá, de su Consejo de Administración, que lleva que hasta 1913 no sea el Banco de Bilbao uno de ámbito nacional.

El cuarto capítulo es obra de Rafael Anes Álvarez, bajo el epígrafe de «Sociedades mercantiles y Banca en Asturias a comienzos del siglo XX». Este trabajo enlaza con el ya clásico de José Ramón García López, Los comerciantes banqueros en el sistema bancario español. Estudio de casas de banca asturianas en el siglo XIX, aparecido en 1987. Vemos ahora, de la pluma de Rafael Anes, cómo surgen, sobre todo, el Banco Asturiano de Industria y Comercio, el Banco de Gijón, el Crédito Industrial Gijonés y el Banco Herrero, con sus estrechas relaciones con el Banco Hispano Americano. La gran importancia industrial de Asturias está detrás de esas aportaciones sobre su estructura crediticia.

El capítulo que cierra la obra es el de Carles Sudrià, «Banca e industria en Cataluña después del 98». Aunque de modo breve, en este capítulo se aborda, de modo inteligente, la cuestión de «crear banca catalana» (p. 344). Como bien dice Carles Sudrià, la respuesta no es evidente. Quizá todo resida, en lo esencial, como señala también Sudrià, en «la dispersión de capitales que se daba en Cataluña» (p. 347). Quizás en lo sucedido con el Banco de Barcelona. El caso es que entonces se confirmó, «en definitiva, lo que ha sido hasta hoy característica propia del mercado financiero catalán: debilidad extrema de la banca autóctona frente a la gran banca nacional y protagonismo destacado de las cajas de ahorros» (p. 348).

Un libro, pues, espléndido, fruto de una conjunción de esfuerzos de españoles, cubanos, puertorriqueños, ciertamente impar que sólo un investigador también impar, como es Pedro Tedde de Lorca, podía haber conseguido como colofón, al menos de momento, del interés colectivo por lo sucedido en torno al 98. 